\title{
Sensory evaluation of blended nectar of guava-papaya
}

\author{
-S.P. SAlVi*, S.N. PAWAR and V.K. Zote
}

Regional Fruit Research Station, Vengurle, SINDHUDURG (M.S.) INDIA

Email : salvisidhesh@rediffmail.com; shalanpawar1@gmail.com and vaishalizote@gmail.com

\section{SUMMARY :}

The experiment was carried out to evaluate effect of different blending proportions of the pulp of guava with papaya pulp. For this experiment, Completely Randomized Design (C.R.D.) was used. During the course of investigation, sensory qualities of blended nectar were analyzed of an interval of 60 days. All the treatments under study showed a remarkable variation with respect to sensory qualities of blended guava - papaya nectar during ambient storage condition. The blended nectar of commercial both the varieties could be stored with optimum sensory qualities by blending in different ratios. Blending the pulp of guava with the pulp of papaya, improve the overall acceptability of blended nectar. Treatment $\mathrm{T}_{2}$ (75:25) found most suitable for blending of guava and papaya nectar.

KEY WORDS : Blending, Design, Sensory, Storage, Overall acceptability

How to cite this paper : Salvi, S.P., Pawar, S.N. and Zote, V.K. (2015). Sensory evaluation of blended nectar of guava-papaya. Internat. J. Proc. \& Post Harvest Technol., 6 (2) : 168-171. 